\title{
Primary amelanotic malignant melanoma
}

\section{of the colon}

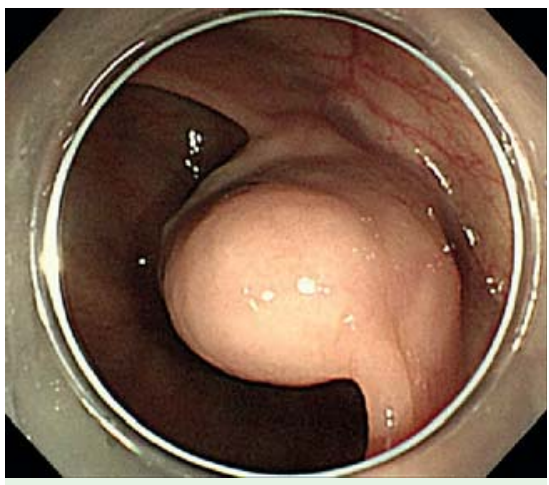

Fig. 1 Colonoscopic view of a 20-mm submucosal tumor in the cecum, thought to be a gastrointestinal stromal tumor.

Malignant melanomas in the gastrointestinal tract are usually metastases from cutaneous melanomas [1], and primary melanomas in the esophagus or anorectal lesions rarely occur. Primary colonic malignant melanoma is extremely rare, with only eight cases previously reported [2]. Although melanomas usually exhibit macroscopic pigmentation, $30 \%$ are amelanotic [3]. Diagnosis of amelanotic melanoma of the gastrointestinal tract by endoscopic examination is difficult owing to its resemblance to gastrointestinal stromal tumor (GIST). We report the case of a patient with amelanotic melanoma of the cecum presenting as a submucosal tumor (SMT), detected by colonoscopy. To our knowledge, this is the first report of primary amelanotic melanoma of the colon. A 39-year-old woman was referred to our hospital for lower abdominal pain. Colonoscopy revealed an SMT (diameter $20 \mathrm{~mm}$ ) in the cecum ( $\nabla$ Fig. 1). Endoscopic ultrasonography revealed a hypoechoic SMT derived from the muscularis propria, which was suspected to be a GIST ( Fig. 2). The patient was offered two possible options: conservative followup and surgery. The patient gave informed consent for surgery and laparoscopic ileocaecal resection was carried out. The resected tumor measured $20 \times 15 \times 10 \mathrm{~mm}$ and its cut surface was milky white in color ( Fig.3). On histological examination,

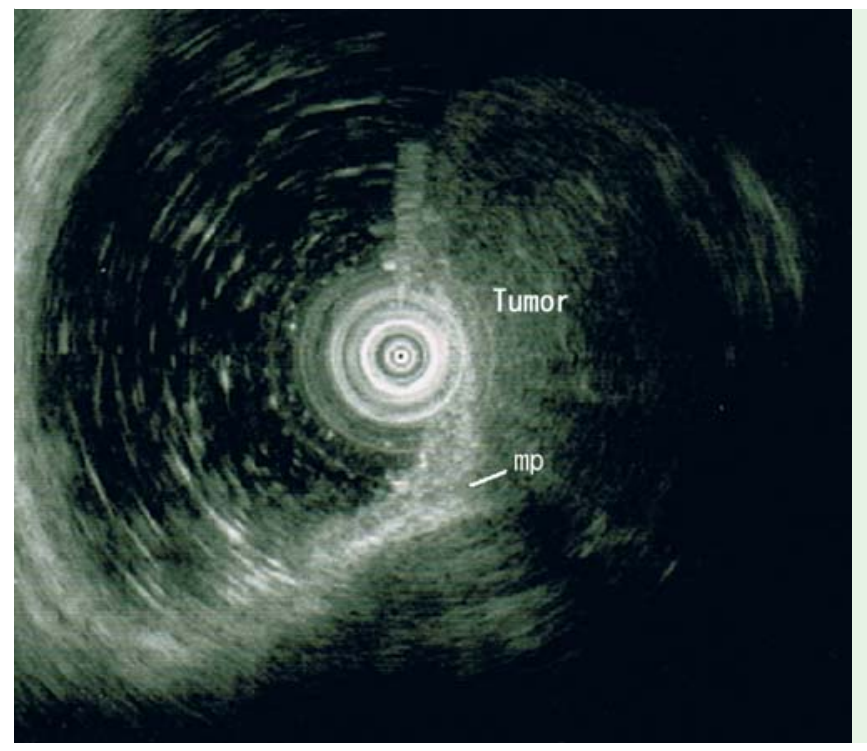

Fig. 2 Endoscopic ultrasonography showing a homogeneous, hypoechoic tumor derived from the muscularis propria (mp).

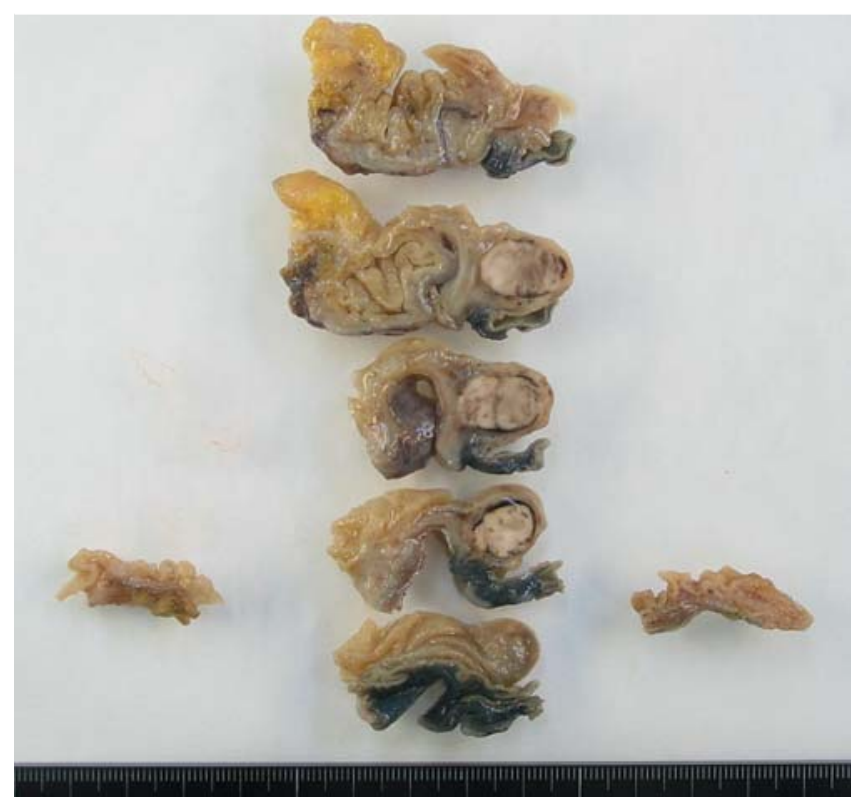

Fig. 3 The resected tumor had a milky white cut surface and measured $20 \times 15 \times 10 \mathrm{~mm}$.

the tumor cells were spindle shaped with abundant cytoplasm ( $\bullet$ Fig. 4 a). In addition, these cells showed strong positive immunohistochemical staining for HMB45 ( Fig. 4 b) but weak positive staining for both smooth muscle antigen and $c$-kit. These characteristics were consistent with malignant melanoma and the tumor was identified as an amelanotic melano- ma. Whole-body computed tomography and positron emission tomography did not reveal any other primary tumors, and thus a diagnosis of primary melanoma of the cecum was established.

\section{Competing interests: None}

Endoscopy_UCTN_Code_CCL_1AD_2AC 


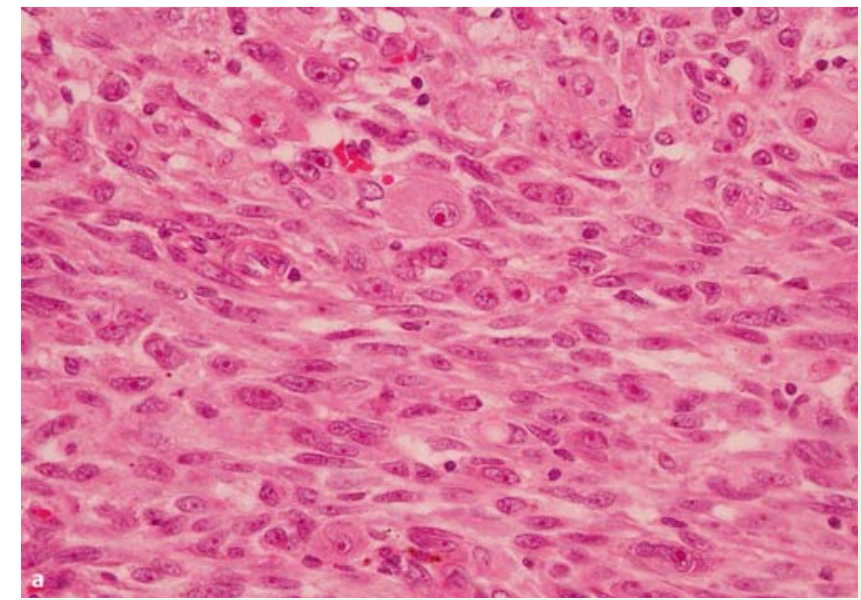

Fig. 4 a Histological section showing spindle-shaped tumor cells with abundant cytoplasm (hematoxylin and eosin; magnification $\times 400$ ). b Strongly positive immunohistochemical staining for HMB-45 (magnification $\times 400)$.

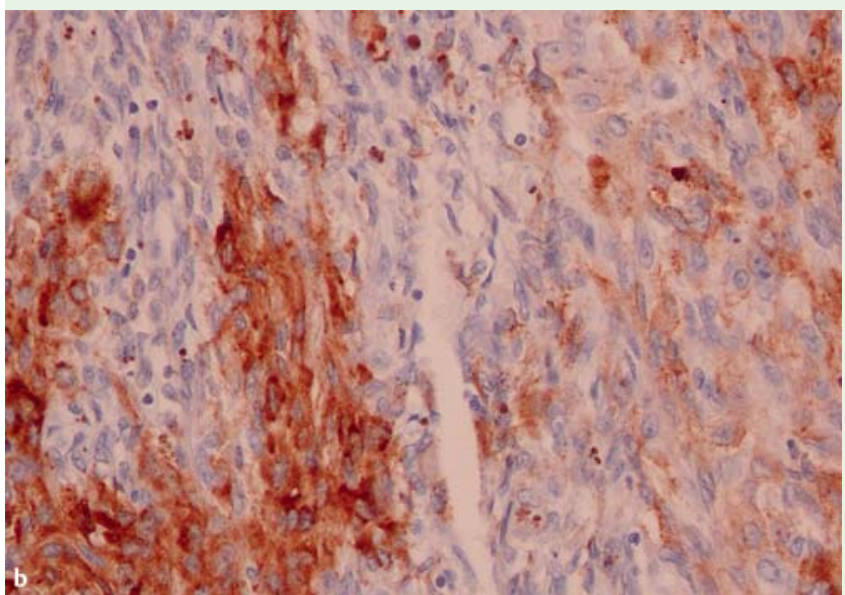

H. Sashiyama, Y. Tsujinaka, Y. Hamahata, O. Tsutsumi, T. Hoshino, Y. Minami, Y. Tsunoda, M. Yano, Y. Sato

Department of Coloproctological Surgery, Tsujinaka Hospital Kashiwanoha, Chiba,

Japan

\section{References}

1 Schuchter LM, Green R, Fraker D. Primary and metastatic diseases in malignant melanoma of the gastrointestinal tract. Curr Opin Oncol $2000 ; 12: 182-185$

2 Kenney B, Dotto J, Homer R et al. Primary malignant melanoma of the transverse colon: report of a case and review of the literature. Int J Surg Pathol 2007; 15: 401 - 407

3 Hilenrand A, Barth TF, Henne-Bruns D et al. Anorectal amelanotic melanoma. Colorectal Dis 2007; 10: 612-615

\section{Bibliography}

DOI $10.1055 / \mathrm{s}-0029-1244148$

Endoscopy 2010; 42: E163-E164

(c) Georg Thieme Verlag KG Stuttgart · New York . ISSN 0013-726X

\section{Corresponding author} H. Sashiyama, MD, PhD

Department of Coloproctological Surgery

Tsujinaka Hospital Kashiwanoha

178-2 Wakashiba

Kashiwa

Chiba

Japan 277-0871

Fax: +81-4-71373738

sasiyama@hotmail.com 